\title{
Scheduling of a Renewable Hybrid Tri-generation
}

\author{
Secil Ercan and Gulgun Kayakutlu
}

\begin{abstract}
Hybrid energy resources are generally accepted with the concern of global pollution and warming. Optimization studies on the detailed scheduling of hybrid energy usage are trying to find solutions for complex problems including uncertainty and lots of data. This paper proposes a stochastic model for detailed scheduling of a tri-generation system using wind and solar sources with thermal collectors. The proposed hourly scheduling will allow balancing the production and consumption as well as giving more realistic commitments the day ahead. The model is currently working with the simulated data and the case application has started.
\end{abstract}

Index Terms-Renewable energy, Tri-generation, CCHP, scheduling, solar energy, wind energy.

\section{INTRODUCTION}

Energy system optimization is studied in different fields of the energy industry. Majority of the studies are focused on investment, design, or operational economics. When it gets to the operational optimization, challenges like load optimization, demand site management and day ahead costing become common objectives. Scheduling is one of the most encountered short-term operational problems. The rising research field is the advanced scheduling of energy production for integrated use of hybrid resources.

This study proposes a new model for detailed scheduling of a renewable tri-generation system with uncertainties. The sample system is designed to include a wind turbine, the solar photovoltaic panels and thermal collectors for the use of a manufacturing plant. Uncertainties in electricity price, energy demand, and output of renewable resources causes the construction of a complex problem. The proposed model uses a stochastic approach to handle the uncertainties of the problem.

The paper is so organized that, a literature review of scheduling studies on renewable energy resources is summarized in the next section. Section III will give a brief definition of CCHP systems and the proposed system. Then, Sections IV and V will be devoted to model the system linearly and stochastically in detail. The concluding remarks will be given in the last section.

\section{LITERATURE REVIEW}

Scheduling of the energy systems concerns operational strategies. The scheduling problem should provide the balance of energy production and consumption because

Manuscript received December 11, 2015; revised May 24, 2016.

Secil Ercan is with Marmara University, Turkey (e-mail: ercansec@itu.edu.tr).

Gulgun Kayakutlu is with Istanbul Technical University, Industrial Engineering Department, Istanbul, Turkey (e-mail: kayakutlu@itu.edu.tr). energy consumption is as important as energy production.

Renewable energy systems have lots of potential advantages on especially environment; however suitable scheduling strategies must be constituted in order to exploit these advantages.

There are several studies that consider the renewable energy systems, combined heating and power (CHP) energy systems, or both of renewable and CHP systems. Scheduling of renewable energy systems are mostly studied. Many of these studies consider the uncertainty of wind or solar energy systems.

Many studies generally prefer to optimize the wind energy system Two-stage stochastic programming method is widely applied for wind energy systems [1]-[5] in order to minimize the cost or maximize the profit. Ref [2] also carried out a bilevel programming framework for similar purpose. Ref. [6] and Ref. [7] used stochastic programming with scenario analysis to schedule the energy system based on wind energy. Ref. [8] also considered the uncertainty of wind energy and implemented mixed-integer linear programming. Ref. [9] applied Monte Carlo simulation and mixed-integer linear programming to solve the unit commitment problem for a wind-based energy system. In another wind-based system study, neural networks were used to maximize the daily revenue [10].

A few studies also optimized the schedule of wind-solar energy systems. Ref. [11] solved the storage scheduling problem and Ref. [12] solved the production scheduling problem by mixed-integer linear programming for a hybrid renewable energy system. To handle with the uncertainty of a wind-solar energy system, Ref. [13] implemented fuzzy optimization where Ref. [14] employed two-stage stochastic programming. Ref. [15] minimized cost and emission by particle swarm optimization. Ref. [16] applied Markov decision process for storage scheduling.

Previous studies investigate the energy systems that only produce electricity. There are a few studies that consider CHP systems based on wind or solar or wind-solar hybrid energy systems. Ref. [17] implemented mixed-integer programming for multi objective optimization and utilized fuzzy decision making whereas Ref. [18] applied bi-population chaotic differential evolution algorithm for a wind-based CHP system. Ref. [19] used mixed integer programming and Ref. [20] applied auto-regressive moving average, time series model and stochastic mixed integer programming for a solar-based CHP system. Ref. [21] modeled wind energy and photovoltaic as a stochastic model in detail. The electricity and thermal power production were scheduled by hybridizing artificial neural network with genetic algorithm and a priority list. Ref. [22] proposed an enhanced cuckoo optimization algorithm for a wind-solar hybrid system that produces both of electricity and heating by 
focusing on energy storage systems.

It is observed that there are not many studies on scheduling of trigeneration energy systems. An example for scheduling of a solar-based CCHP system which uses PV model is proposed by Ref. [23]. They solved the scheduling problem with linear programming.

\section{CCHP SYSTEM}

Trigeneration systems produce three types of energy, simultaneously. These systems utilize waste heat which gets out while producing electricity. The most known form of trigeneration is combined cooling, heating and power systems which is called as CCHP. CCHP is a decentralized energy system which does not depend on a central system. Therefore, transmission losses and any interruptions are less than the traditional energy systems. Production point is close to consumption point. CCHP is generally fed by naturalgas based power generation units such as boilers, gas engines, gas turbines, Stirling engines, fuel cells [24].

The main power generation units produce the electricity and heating as is the case with CHP. The difference from CHP is converting the electricity and heating to cooling by using electrical chiller and absorption chiller or adsorption chiller. A typical CCHP system is shown in Fig. 1.

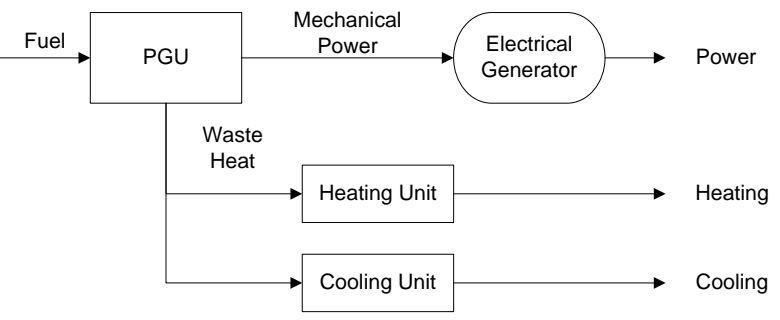

Fig. 1. A typical CCHP system.

This study considers a trigeneration energy system that mainly utilized wind and solar energy (shown in Fig. 2). When wind and solar energy are not enough, electric will be purchased form the grid or natural gas. Photovoltaic (PV) systems and solar thermal collectors will take place in the system by utilizing the solar. PV units only produce electricity while solar thermal collectors can produce both of electricity and heating.

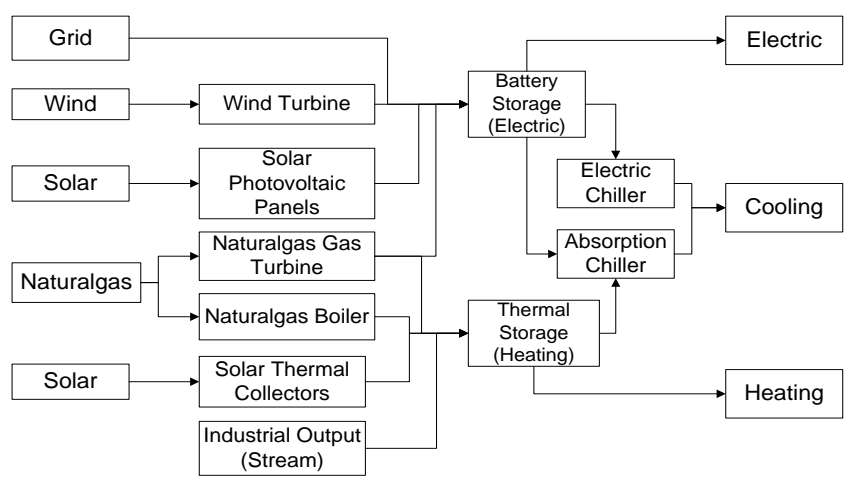

Fig. 2. The proposed CCHP system.

The system tries to satisfy the demand of electricity and heating from directly auto-production or grid. For industrial systems, industrial outputs such as steam will also support the heating output. Remaining part of the production is stored in the battery and thermal storage devices. Since outputs of wind and solar energy are fluctuated, electricity prices and power demands are uncertain, storage has a significant role. Battery and thermal storage devices not only meet the following period's electricity and heating demand but also provide the electricity and heating to the electrical and absorption chiller in order to convert them to cooling.

\section{SySTEM MOdELLING}

\section{A. Definitions}

Before explaining the objective function and constraints in detail, the subscripts, decision variables, and parameters used in mathematical model are defined. Table I gives this nomenclature.

\section{B. Objective Function}

The objective of the model is to minimize the total production and stock costs. Since the production and consumption of the energy is hourly scheduled, total cost function is equal to the sum of each hour's cost. Table II displays the cost items for hour $t$. Since gas turbine provides both electricity and heating, the production costs depend on efficiencies. When efficiency increases, unit cost decreases.

We want to minimize the daily costs. Thus, the objective function is the sum of these cost items over 24 hours.

$$
\begin{aligned}
& \min \sum_{t=1}^{24}\left(\beta_{G, t} E_{G, t}+\beta_{G T, t} E_{G T, t}+\beta_{W T, t} E_{W T, t}+\beta_{P V, t} E_{P V, t}\right) \\
& +\sum_{t=1}^{24}\left(\beta_{G T, t} Q_{G T, t}+\beta_{B, t} Q_{B, t}+\beta_{T C, t} Q_{T C, t}+\beta_{S, t} Q_{S, t}\right) \\
& +\sum_{t=1}^{24}\left(\theta_{e t} s_{e t}+\theta_{q t} s_{q t}\right)+\sum_{t=1}^{24}\left(\gamma_{e t} R_{e t}+\gamma_{q t} R_{q t}\right)
\end{aligned}
$$

TABLE I: NOMENCLATURE OF SUBSCRIPTS, DECISION VARIABLES, AND

\begin{tabular}{|l|l|}
\hline \multicolumn{2}{|l}{ PARAMETERS } \\
\hline$G$ & Grid \\
\hline$G T$ & Gas turbine \\
\hline$W T$ & Wind turbine \\
\hline$P V$ & Photovoltaic \\
\hline$B$ & Boiler \\
\hline$T C$ & Thermal collector \\
\hline$S$ & Steam \\
\hline$e$ & Electricity \\
\hline$q$ & Heating \\
\hline$r$ & Cooling (refrigeration) \\
\hline$t$ & Time (hour) \\
\hline$A C$ & Absorption chiller \\
\hline$E C$ & Electric chiller \\
\hline & \multicolumn{1}{c|}{ Decision variables } \\
\hline$E_{G, t}$ & $\begin{array}{l}\text { Amount of electricity imported from the grid in } \\
\text { hour } t\end{array}$ \\
\hline$E_{G T, t}$ & $\begin{array}{l}\text { Amount of electricity produced by naturalgas gas } \\
\text { turbine in hour } t\end{array}$ \\
\hline$E_{W T, t}$ & $\begin{array}{l}\text { Amount of electricity produced by wind turbine in } \\
\text { hour } t\end{array}$ \\
\hline$E_{P V, t}$ & $\begin{array}{l}\text { Amount of electricity produced by photovoltaic } \\
\text { panels in hour } t\end{array}$ \\
\hline$Q_{G T, t}$ & $\begin{array}{l}\text { Amount of heating produced by naturalgas gas } \\
\text { turbine in hour } t\end{array}$ \\
\hline$Q_{B, t}$ & $\begin{array}{l}\text { Amount of heating produced by naturalgas boiler } \\
\text { in hour } t\end{array}$ \\
\hline &
\end{tabular}




\begin{tabular}{|c|c|}
\hline$Q_{T C, t}$ & $\begin{array}{l}\text { Amount of heating produced by thermal } \\
\text { collectors in hour } t\end{array}$ \\
\hline$Q_{S, t}$ & $\begin{array}{l}\text { Amount of heating produced by steam as an } \\
\text { industrial output in hour } t\end{array}$ \\
\hline$s_{e t}$ & Amount of storage for electricity in hour $t$ \\
\hline$s_{q t}$ & Amount of storage for heating in hour $t$ \\
\hline$R_{e t}$ & $\begin{array}{l}\text { Amount of cooling (refrigeration) produced by } \\
\text { utilizing electricity in hour } t\end{array}$ \\
\hline$R_{q t}$ & $\begin{array}{l}\text { Amount of cooling (refrigeration) produced by } \\
\text { utilizing heating in hour } t\end{array}$ \\
\hline$E_{r t}$ & $\begin{array}{l}\text { Electricity required by electric chiller to produce } \\
\text { cooling in hour } t\end{array}$ \\
\hline$Q_{r t}$ & $\begin{array}{l}\text { Heating required by electric chiller to produce } \\
\text { cooling in hour } t\end{array}$ \\
\hline \multicolumn{2}{|r|}{ Parameters } \\
\hline$\beta_{., t}$ & $\begin{array}{l}\text { Coefficient of production or purchasing cost in } \\
\text { hour } t \text { (for G, GT, WT, PV, B, TC, S) }\end{array}$ \\
\hline$\eta_{e}, \eta_{h}$ & $\begin{array}{l}\text { Efficiency of gas turbine for electricity and } \\
\text { heating, respectively }\end{array}$ \\
\hline$\theta_{e t}, \theta_{q t}$ & $\begin{array}{l}\text { Coefficient of storage cost in hour } t \text { for electricity } \\
\text { and heating, respectively }\end{array}$ \\
\hline$\gamma_{e t}, \gamma_{q t}$ & $\begin{array}{l}\text { Coefficient of cost for producing cooling in hour } t \\
\text { (for electricity and heating, respectively) }\end{array}$ \\
\hline$d_{e t}, d_{q t}, d_{r t}$ & $\begin{array}{l}\text { Demand amount in hour } t \text { for electricity, heating } \\
\text { and cooling, respectively }\end{array}$ \\
\hline$\rho_{. t}$ & Coefficient of gas emission \\
\hline$c_{e t}, c_{q t}$ & $\begin{array}{l}\text { Capacity of storage in hour } t \text { for electricity and } \\
\text { heating, respectively }\end{array}$ \\
\hline$\lambda_{., t}$ & Production capacity in hour $t$ (for G, GT, B, S) \\
\hline$K$ & Allowable maximum $\mathrm{CO}_{2}$ emission \\
\hline$C O P_{E C}$ & $\begin{array}{l}\text { Coefficient of performance for electric chiller } \\
\text { (EC) }\end{array}$ \\
\hline$C O P_{A C}$ & $\begin{array}{l}\text { Coefficient of performance for absorption chiller } \\
\text { (AC) }\end{array}$ \\
\hline
\end{tabular}

TABLE II: COST ITEMS FOR AN HOUR

\begin{tabular}{|l|l|}
\hline \multicolumn{1}{|c|}{ Cost item } & \multicolumn{1}{|c|}{ Formula } \\
\hline $\begin{array}{l}\text { Electricity } \\
\text { production cost }\end{array}$ & $\begin{array}{l}\beta_{G, t} E_{G, t}+\left(\beta_{G T, t} / \eta_{e}\right) E_{G T, t} \\
+\beta_{W T, t} E_{W T, t}+\beta_{P V, t} E_{P V, t}\end{array}$ \\
\hline $\begin{array}{l}\text { Heating } \\
\text { production cost }\end{array}$ & $\begin{array}{l}\left(\beta_{G T, t} / \eta_{h}\right) Q_{G T, t}+\beta_{B, t} Q_{B, t} \\
+\beta_{T C, t} Q_{T C, t}+\beta_{S, t} Q_{S, t}\end{array}$ \\
\hline Storage cost & $\theta_{e t} s_{e t}+\theta_{q t} s_{q t}$ \\
\hline $\begin{array}{l}\text { Cooling } \\
\text { production cost }\end{array}$ & $\gamma_{e t} R_{e t}+\gamma_{q t} R_{q t}$ \\
\hline
\end{tabular}

\section{Objective Function}

Energy balance constraints: Electric (power), heating and cooling demands must be satisfied by that period's production and previous period's storage. After the satisfaction of the demands, remaining is hold in battery and thermal storage. Power balance

$$
\begin{aligned}
& E_{G, t}+E_{G T, t}+E_{W T, t}+E_{P V, t}+s_{e t}-d_{e t} \\
& -E_{r t}-s_{e, t+1}=0, \quad \forall \mathrm{t}
\end{aligned}
$$

Heat balance

$$
\begin{aligned}
& Q_{G T, t}+Q_{B, t}+Q_{T C, t}+Q_{S, t}+s_{q t}-d_{q t} \\
& -Q_{r t}-s_{q, t+1}=0, \forall \mathrm{t}
\end{aligned}
$$

Cooling balance

$$
R_{e t}+R_{q t}-d_{r t}=0, \forall \mathrm{t}
$$

Storage capacity constraints (battery and thermal storage devices): Electricity and heating are stored as energy not power. The capacities are based on chosen battery and thermal storage device.

$$
\begin{aligned}
& s_{e t} \leq c_{e t}, \quad \forall t \\
& s_{q t} \leq c_{q t}, \quad \forall t
\end{aligned}
$$

Production capacity constraints:

Capacity for wind turbine is based on the probability density function of wind speed.

$$
E_{W T, t} \leq f_{W T}(v), \forall t
$$

where $v$ denotes wind speed. Since wind speed is uncertain, we consider its distribution as empirical distribution.

The amount of solar irradiance affects the capacity for $\mathbf{P V}$ panels and thermal collectors. Both of them are based on solar irradiance $(I)$ with different functions.

$$
\begin{aligned}
& E_{P V, t} \leq f_{P V}(I), \forall t \\
& Q_{T C, t} \leq f_{T C}(I), \quad \forall t
\end{aligned}
$$

Naturalgas boiler and naturalgas gas turbine capacities do not change after the design of the system. On the other hand, capacities of gas turbine for electricity and for heating depend on their efficiencies. If efficiency is high, then there is more capacity for that energy type.

$$
\begin{gathered}
Q_{B, t} \leq \lambda_{B, t}, \quad \forall t \\
E_{G T, t} \leq \eta_{e} \lambda_{G T, t}, \quad \forall t \\
Q_{G T, t} \leq \eta_{h} \lambda_{G T, t}, \quad \forall t
\end{gathered}
$$

There is also an upper limit for purchasing electricity from grid.

$$
E_{G, t} \leq \lambda_{G, t}, \quad \forall t
$$

$\mathrm{CO}_{2}$ emission: Environmental impact of gas emissions is another significant fact that must be considered. Since $\mathrm{CO}_{2}$ emission causes global warming, total emission should be restricted by an upper bound.

$$
\begin{aligned}
& \sum_{t=1}^{24}\left(\rho_{G, t} E_{G, t}+\rho_{G T, t} E_{G T, t}+\rho_{W T, t} E_{W T, t}+\rho_{P V, t} E_{P V, t}\right) \\
& +\sum_{t=1}^{24}\left(\rho_{G T, t} Q_{G T, t}+\rho_{B, t} Q_{B, t}+\rho_{T C, t} Q_{T C, t}+\rho_{S, t} Q_{S, t}\right) \\
& \leq K
\end{aligned}
$$

Energy equations: In addition to these constraints, there are a few equations about energy transformation, availability.

Cooling by the chillers cannot be directly transformed as imported electricity and heating. Amount of produced cooling is calculated by multiplying the required electricity and heating with coefficient of performance (COP) which describes efficiencies of chillers. 


$$
\begin{aligned}
& R_{e t}=E_{r t} C O P_{E C}, \forall t \\
& R_{q t}=Q_{r t} C O P_{A C}, \forall t
\end{aligned}
$$

Since cooling is produced by electricity and heating imported from storages, imported electricity and heating should not exceed the amount in storages.

$$
\begin{gathered}
E_{r t} \leq s_{e t}, \quad \forall t \\
Q_{r t} \leq s_{q t}, \quad \forall t
\end{gathered}
$$

\section{StOCHASTIC MOdELLING}

Stochastic programming is used to handle the uncertainties detected during the simulation of the model. Uncertainty may be in constraints or in any coefficient of objective function.

Let $A(x)$ be the event that is desired to realize where $Z$ is the random vector that includes uncertainty.

$$
A(x)=\left\{g_{j}(x, Z) \leq 0\right\}
$$

Then, in stochastic programming, probabilistic constraint for event $A(x)$ is formulated as in the following [25].

$$
\operatorname{Pr}\{A(x)\} \geq p \Rightarrow \operatorname{Pr}\left\{g_{j}(x, Z) \leq 0\right\} \geq p
$$

$p$ has values in a range between 0 and 1 .

If the uncertainty is in the objective function, the objective becomes to minimize (or maximize) the expected value of the objective function.

$$
\begin{gathered}
\min \sum_{t} c_{t} x_{t} \Rightarrow \quad \min \sum_{t} E\left[c_{t} x_{t}\right] \\
E[X]=\sum_{k} p_{k} x_{k} \Rightarrow \min \sum_{t} \sum_{k} p_{k}\left(c_{t}^{k} x_{t}\right)
\end{gathered}
$$

where the sum of $p_{k}$ 's is 1 , and $c^{k}$ denotes different scenarios for the coefficient of objective function.

In this study,

- Electricity price

- Demand for electricity, heating, and cooling

- Output of wind and solar energy have uncertain properties.

Let $p_{k}$ be the probability for electricity price, $p_{e}$ be the probability for electricity demand, $p_{h}$ be the probability for heating demand, $p_{r}$ be the probability for cooling demand, $p_{v}$ be the probability for wind speed, $p_{I}$ be the probability for solar irradiance. Then, stochastic model of the system is the following:

$$
\begin{aligned}
& \min \sum_{t=1}^{24}\left(\sum_{k=1}^{K} p_{G, k}\left(\beta_{G, t} E_{G, t}\right)+\beta_{G T, t} E_{G T, t}+\beta_{W T, t} E_{W T, t}+\beta_{P V, t} E_{P V, t}\right) \\
& +\sum_{t=1}^{24}\left(\beta_{G T, t} Q_{G T, t}+\beta_{B, t} Q_{B, t}+\beta_{T C, t} Q_{T C, t}+\beta_{S, t} Q_{S, t}\right) \\
& +\sum_{t=1}^{24}\left(\theta_{e t} s_{e t}+\theta_{q t} s_{q t}\right)+\sum_{t=1}^{24}\left(\gamma_{e t} R_{e t}+\gamma_{q t} R_{q t}\right) \\
& \text { s.t. }
\end{aligned}
$$

$$
\begin{gathered}
\operatorname{Pr}\left\{E_{G, t}+E_{G T, t}+E_{W T, t}+E_{P V, t}+s_{e t}-d_{e t}-E_{r t}-s_{e, t+1}=0\right\} \geq p_{e} \\
\operatorname{Pr}\left\{Q_{G T, t}+Q_{B, t}+Q_{T C, t}+Q_{S, t}+s_{q t}-d_{q t}-Q_{r t}-s_{q, t+1}=0\right\} \geq p_{q} \\
\operatorname{Pr}\left\{R_{e t}+R_{q t}-d_{r t}=0\right\} \geq p_{r} \\
s_{e t} \leq c_{e t} \\
s_{q t} \leq c_{q t} \\
\operatorname{Pr}\left\{E_{W T, t} \leq f_{W T}(v)\right\} \geq p_{v} \\
\operatorname{Pr}\left\{E_{P V, t} \leq f_{P V}(I)\right\} \geq p_{I} \\
\operatorname{Pr}\left\{Q_{T C, t} \leq f_{T C}(I)\right\} \geq p_{I} \\
Q_{B, t} \leq \lambda_{B, t} \\
E_{G T, t} \leq \eta_{e} \lambda_{G T, t} \\
Q_{G T, t} \leq \eta_{h} \lambda_{G T, t} \\
E_{G, t} \leq \lambda_{G, t}, \forall t \\
\sum_{t=1}^{24}\left(\rho_{G, t} E_{G, t}+\rho_{G T, t} E_{G T, t}+\rho_{W T, t} E_{W T, t}+\rho_{P V, t} E_{P V, t}\right) \\
+\sum_{t=1}^{24}\left(\rho_{G T, t} Q_{G T, t}+\rho_{B, t} Q_{B, t}+\rho_{T C, t} Q_{T C, t}+\rho_{S, t} Q_{S, t}\right) \leq K \\
R_{e t}=E_{r t} C O P_{E C} \\
R_{q t}=Q_{r t} C O P_{A C} \\
E_{r t} \leq s_{e t} \\
Q_{r t} \leq s_{q t}
\end{gathered}
$$

All variables are nonnegative

All constraints are for all $t=1,2, \ldots, 24$.

\section{CONCLUSiOnS}

A hybrid renewable trigeneration system model, comprising wind turbine, photovoltaic panels, thermal collectors, naturalgas gas turbine and boiler has been developed. Conventional systems that produce only electricity becomes not sufficient for any plant of building, especially for industrial plants where heating and cooling are also necessary in production processes. Energy demands are generally uncertain at these industrial plants because of uncertainty in sales demands. In addition, renewable energy resources are more environmental friendly whether the system is conventional or CHP or CCHP. Considering all of these aspects, uncertainties in electricity price, demands, and outputs of wind-solar systems have been considered in order to schedule this trigeneration system.

The proposed system has been mathematically modeled considering uncertainties. Further research will solve this model using a proper stochastic optimization method.

\section{REFERENCES}

[1] R. M. Lima, A. Q. Novais, and A. J. Conejo, "Weekly self-scheduling, forward contracting, and pool involvement for an electricity producer. An adaptive robust optimization approach," European Journal of Operational Research, vol. 240, no. 2, pp. 457-475, 2015.

[2] J. M. Morales, M. Zugno, S. Pineda, and P. Pinson, "Electricity market clearing with improved scheduling of stochastic production," 
European Journal of Operational Research, vol. 235, no. 3, pp. 765-774, 2014.

[3] H. Pandžić, J. M. Morales, A. J. Conejo, and I. Kuzle, "Offering model for a virtual power plant based on stochastic programming," Applied Energy, vol. 105, pp. 282-292, 2013.

[4] G. Pritchard, G. Zakeri, and A. Philpott, "A single-settlement, energy-only electric power market for unpredictable and intermittent participants," Operations Research, vol. 58, no. 4, pp. 1210-1219, 2010.

[5] Z. Tan, L. Ju, H. Li, J. Li, and H. Zhang, "A two-stage scheduling optimization model and solution algorithm for wind power and energy storage system considering uncertainty and demand response," International Journal of Electrical Power \& Energy Systems, vol. 63, pp. 1057-1069, 2014.

[6] A. Tuohy, P. Meibom, E. Denny, and M. O’Malley, "Unit commitment for systems with significant wind penetration," IEEE Transactions on Power Systems, vol. 24, no. 2, pp. 592-601, 2009.

[7] J. Hetzer, D. C. Yu, and K. Bhattarai, "An economic dispatch model incorporating wind power," IEEE Transactions on Energy Conversion, vol. 23, no. 2, pp. 603-611, 2008.

[8] D. Choling, P. Yu, and B. Venkatesh, "Effects of security constraints on unit commitment with wind generators," in Proc. IEEE Power \& Energy Society General Meeting, Calgary, 2009, pp. 1-6.

[9] G. J. Osório, J. M. Lujano-Rojas, J. C. O. Matias, and J. P. S. Catalão, "A new scenario generation-based method to solve the unit commitment problem with high penetration of renewable energies," International Journal of Electrical Power \& Energy Systems, vol. 64 pp. 1063-1072, 2015.

[10] A. K. Varkani, A. Daraeepour, and H. Monsef, "A new self-scheduling strategy for integrated operation of wind and pumped-storage power plants in power markets," Applied Energy, vol. 88, no. 12, pp. 5002-5012, 2011.

[11] G. Cau, D. Cocco, M. Petrollese, S. K. Kær, and C. Milan, "Energy management strategy based on short-term generation scheduling for a renewable microgrid using a hydrogen storage system," Energy Conversion and Management, vol. 87, pp. 820-831, 2014.

[12] A. M. Zein Alabedin, E. F. El-Saadany, and M. M. A. Salama, "Generation scheduling in microgrids under uncertainties in power generation," in Proc. IEEE Electrical Power and Energy Conference, London, Ontario, 2012, pp. 133-138.

[13] R.-H. Liang and J.-H. Liao, "A fuzzy-optimization approach for generation scheduling with wind and solar energy systems," IEEE Transactions on Power Systems, vol. 22, no. 4, pp. 1665-1674, 2007.

[14] R. Domínguez, A. J. Conejo, and M. Carrión, "Operation of a fully renewable electric energy system with CSP plants," Applied Energy, vol. 119, pp. 417-430, 2014.

[15] A. Y. Saber and G. K. Venayagamoorthy, "Resource scheduling under uncertainty in a smart grid with renewables and plug-in vehicles," IEEE Systems Journal, vol. 6, no. 1, pp. 103-109, 2012.

[16] Y. Zhang and M. van der Schaar, "Structure-aware stochastic storage management in smart grids," IEEE Journal of Selected Topics in Signal Processing, vol. 8, no. 6, pp. 1098-1110, 2014.

[17] J. Aghaei and M.-I. Alizadeh, "Multi-objective self-scheduling of CHP (combined heat and power)-based microgrids considering demand response programs and ESSs (energy storage systems)," Energy, vol 55, pp. 1044-1054, 2013.

[18] C. Peng, H. Sun, J. Guo, and G. Liu, "Dynamic economic dispatch for wind-thermal power system using a novel bi-population chaotic differential evolution algorithm," International Journal of Electrical Power \& Energy Systems, vol. 42, no. 1, pp. 119-126, 2012.

[19] X. Guan, Z. Xu, and Q.-S. Jia, "Energy-efficient buildings facilitated by microgrid," IEEE Transactions on Smart Grid, vol. 1, no. 3, pp. 243-252, 2010.

[20] P. Liu, Y. Fu, and A. K. Marvasti, "Multi-stage stochastic optimal operation of energy-efficient building with combined heat and power system," Electric Power Components and Systems, vol. 42, no. 3-4, pp. 327-338, 2014.

[21] A. A. ElDesouky, "Security constrained generation scheduling for grids incorporating wind, photovoltaic and thermal power," Electric Power Systems Research, vol. 116, pp. 284-292, 2014.

[22] S. Mohammadi and A. Mohammadi, "Stochastic scenario-based model and investigating size of battery energy storage and thermal energy storage for micro-grid," Electrical Power and Energy Systems, vol. 61, pp. 531-546, 2014.

[23] K. Wongvisanupong and N. Hoonchareon, "Optimal scheduling of hybrid CCHP and PV operation for shopping complex load," in Proc. 10th International Conference on Electrical Engineering/ Electronics, Computer, Telecommunications and Information Technology, Krabi, Thailand, 2013, pp. 667-672.

[24] F. A. Al-Sulaiman, F. Hamdullahpur, and I. Dincer, "Trigeneration: A comprehensive review based on prime movers," International Journal of Energy Research, vol. 35, pp. 233-258, 2011.

[25] A. Shapiro, D. Dentcheva, and A. Ruszczynski, "Lectures on stochastic programming: modeling and theory," Society for Industrial and Applied Mathematics, Mathematical Programming Society, Philadelphia, 2009.

Secil Ercan obtained an undergraduate degree in industrial engineering from Istanbul Technical University (ITU), in 2009. She also obtained a master of science degree in industrial engineering from ITU, in 2011. She has studied classification by using support vector machines in her master thesis. She started her PhD in industrial engineering in the same year.

She studies mathematical modeling, energy optimization, and artificial neural networks in general. She also worked at ITU as a research assistant for four years, and started to work at Marmara University since February 2015

Gulgun Kayakutlu is currently lecturing on operations research and knowledge systems at Istanbul Technical University, Industrial Engineering Department, Istanbul, Turkey. In parallel, she is leading innovation and knowledge based projects.

Dr. Kayakutlu has chosen to be in the academic world after having occupied several executive management positions like being a project leader in International Energy Agency, Paris. She is a fellow of Enovation International and works as a secretary for IFIPTC12.6 Workgroup. She has more than fifty papers published in Indexed Scientific Reviews. 